\title{
Basolateral Amygdala Cdk5 Activity Mediates Consolidation and Reconsolidation of Memories for Cocaine Cues
}

\author{
Fang-qiong Li, ${ }^{1,2 *}$ Yan-xue Xue, ${ }^{2 *}$ Ji-shi Wang, ${ }^{1}$ Qin Fang, ${ }^{1}$ Yan-qin Li, ${ }^{2}$ Wei-Li Zhu, ${ }^{2}$ Ying-ying He, ${ }^{1}$ Jian-feng Liu, ${ }^{2}$ \\ Li-fen Xue, ${ }^{2}$ Yavin Shaham, ${ }^{3}$ and Lin $\mathrm{Lu}^{2}$ \\ ${ }^{1}$ School of Pharmacy and Affiliated Hospital of Guiyang Medical University, Guiyang 550004, China, ${ }^{2}$ National Institute on Drug Dependence, Peking \\ University, Beijing 100191, China, and ${ }^{3}$ Behavioral Neuroscience Branch, Intramural Research Program, National Institute on Drug Abuse-National \\ Institutes of Health, Baltimore, Maryland 21224
}

Cocaine use and relapse involves learned associations between cocaine-associated environmental contexts and discrete stimuli and cocaine effects. Initially, these contextual and discrete cues undergo memory consolidation after being paired with cocaine exposure. During abstinence, cocaine cue memories can undergo memory reconsolidation after cue exposure without the drug. We used a conditioned place preference (CPP) procedure in rats to study the role of neuronal protein kinase cyclin-dependent kinase $5(\mathrm{Cdk} 5)$ in consolidation and reconsolidation of cocaine cue memories. We found that the expression of cocaine CPP in drug-free tests $1 \mathrm{~d}$ after CPP training (four pairings of $10 \mathrm{mg} / \mathrm{kg}$ cocaine with one context and four pairings of saline with a different context) increased Cdk5 activity, and levels of the Cdk5 activator p35 in basolateral but not central amygdala. We also found that basolateral (but not central) amygdala injections of the Cdk5 inhibitor $\beta$-butyrolactone (100 ng/side) immediately (but not $6 \mathrm{~h}$ ) after cocaine-context pairings during training prevented subsequent cocaine CPP expression. After training, acute basolateral (but not central) amygdala $\beta$-butyrolactone injections immediately before testing prevented the expression of cocaine CPP; this effect was also observed on a second test performed $1 \mathrm{~d}$ later, suggesting an effect on reconsolidation of cocaine cue memories. In support, basolateral $\beta$-butyrolactone injections, given immediately (but not $6 \mathrm{~h}$ ) after a single exposure to the cocaine-paired context, prevented cocaine CPP expression 1 and $14 \mathrm{~d}$ after the injections. Results indicate that basolateral amygdala Cdk5 activity is critical for consolidation and reconsolidation of the memories of cocaine-associated environmental cues.

\section{Introduction}

Early studies by Wikler (1973) and subsequent investigations (O’Brien et al., 1992) suggest that environmental cues associated with drug taking contribute to compulsive drug use and relapse. Based on these studies, Wikler, O'Brien, and others proposed that pavlovian conditioning processes play major roles in drug addiction and that drug cue memories persist during prolonged abstinence periods (Wikler, 1973; Stewart et al., 1984; O'Brien et al., 1992). In laboratory rats, studies using second-order reinforcement schedules and extinction-reinstatement procedures demonstrate that cues associated with drug effects maintain drug-seeking behavior (Goldberg, 1975; Everitt and Robbins, 2000) and reinstate drug seeking after prolonged abstinence periods (See, 2002; Ciccocioppo et al., 2004; Lu et al., 2004).

\footnotetext{
Received April 25, 2010; revised May 25, 2010; accepted June 16, 2010.

This work was supported in part by National Basic Research Program of China Grant 2007CB512302, Natural Science Foundation of Beijing Municipality Grants 09G0762 and 7092058, and Natural Science Foundation of Guizhou Province Grant 2008-59.

The authors declare no competing financial interests.

${ }^{*}$ F.-q. Li and Y.-x. Xue contributed equally to this work.

Correspondence should be addressed to either of the following: Prof. Ji-shi Wang at the above address, E-mail: jswang_yg@yahoo.com; or Prof. Lin Lu at the above address, E-mail: linlu@bjmu.edu.cn.

Y.-q. Li's present address: Department of Pharmacology and Chemical Biology, University of Pittsburgh, Pittsburgh, PA 15261

DOI:10.1523/JNEUROSCI.2112-10.2010

Copyright $\odot 2010$ the authors $\quad 0270-6474 / 10 / 3010351-09 \$ 15.00 / 0$
}

Two main mechanisms for establishment and persistence of memories for cues paired with rewarding or aversive stimuli are consolidation - a time-dependent process that leads to permanent storage of newly acquired memory (McGaugh, 1966, 2000) —and reconsolidation - a time-dependent process wherein consolidated memory items are rendered transiently malleable shortly after its reactivation (Misanin et al., 1968; Nader et al., 2000; Dudai, 2006). The cellular mechanisms of consolidation and reconsolidation of memories for drug-associated cues can be assessed in a pavlovian conditioned place preference (CPP) procedure (Cervo et al., 1997; Beninger and Gerdjikov, 2004; Miller and Marshall, 2005), in which during the training phase one context is paired with drug injections, whereas another context is paired with vehicle injections (Tzschentke, 1998; Bardo and Bevins, 2000). During subsequent drug-free CPP tests, rats choose between the drugand vehicle-paired contexts; increased preference for the drug context serves as measures of drug reward (Mucha et al., 1982) and incentive motivational effects of drug cues (Mueller and Stewart, 2000).

Cyclin-dependent kinase $5(\mathrm{Cdk} 5)$ is a neuronal serine/threonine protein kinase whose function is controlled by homologous neuron-specific regulatory cofactors: p35 or p39 (Dhavan and Tsai, 2001; Benavides and Bibb, 2004; Cheung et al., 2006). Cdk5 plays a role in several neuronal and cellular processes, including neuronal migration and differentiation (Ohshima et al., 1996; Chae et al., 1997), axonal growth (Nikolic et al., 1998), membrane transport (Paglini and Cáceres, 2001), and dopamine 
signaling (Bibb et al., 2001). Cocaine exposure increases striatal Cdk5 levels and activity (Bibb et al., 2001; Kansy et al., 2004). Additionally, genetic or pharmacological inhibition of nucleus accumbens Cdk5 function enhances intravenous cocaine reward (as assessed by a progressive ratio reinforcement schedule), cocaine CPP, cocaine psychomotor stimulation, and cocaineinduced potentiation of responding for reward cues (Benavides et al., 2007; Taylor et al., 2007).

Results from several studies indicate a critical role of Cdk5 activity in the septo-hippocampal system in consolidation and extinction of conditioned fear memories (Fischer et al., 2002, 2003a,b; Sananbenesi et al., 2007). Here, we used the CPP procedure to study the role of Cdk5 and its activator p 35 in the basolateral amygdala in consolidation and reconsolidation of cocaine cue memories. We studied the basolateral amygdala because of the critical roles of this brain site in consolidation and reconsolidation of aversive and appetitive memories (Nader et al., 2000; McGaugh, 2004; Tronson and Taylor, 2007; Everitt et al., 2008), including memories of cocaine cues (Kruzich and See, 2001; Lee et al., 2005, 2006; Fuchs et al., 2006; Bernardi et al., 2009).

\section{Materials and Methods}

\section{Subjects}

Two hundred fifty-seven male Sprague Dawley rats, weighing 220-240 g, were obtained from the Laboratory Animal Center, Peking University Health Science Center. Twelve of these rats were used for assessing basal levels of Cdk5 and p35 but did not participate in the behavioral experiments. The rats were housed in groups of five in a temperature $\left(23 \pm 2^{\circ} \mathrm{C}\right)$ - and humidity $(50 \pm 5 \%)$-controlled animal facility with ad libitum access to food and water. The rats were kept on a reverse $12 \mathrm{~h}$ light/dark cycle. All experimental procedures were performed in accordance with the National Institutes of Health Guide for the Care and Use of Laboratory Animals and were approved by the local committee of animal use and protection.

\section{Surgery}

Rats (weighing 320-350 g when surgery began) were anesthetized with sodium pentobarbital (50 mg/kg, i.p.). Guide cannulae (23 gauge; Plastics One) were bilaterally implanted $1 \mathrm{~mm}$ above the basolateral or central amygdala (BLA and CeA), respectively. The BLA coordinates (Paxinos and Watson, 2005) were anterior/posterior, $-2.9 \mathrm{~mm}$; medial/ lateral, $\pm 5.0 \mathrm{~mm}$; dorsal/ventral, $-8.5 \mathrm{~mm}$; and the CeA coordinates were anterior/posterior, $-2.9 \mathrm{~mm}$; medial/lateral, $\pm 4.2 \mathrm{~mm}$; dorsal/ventral, -7.8 $\mathrm{mm}$. These coordinates are based on our previous work (Lu et al., 2005, 2007; Li et al., 2008; Wang et al., 2008). The cannulae were anchored to the skull with stainless-steel screws and dental cement. A stainless-steel stylet blocker was inserted into each cannula to keep it patent and prevent infection. The rats were allowed to recover for 5-7 d after surgery.

\section{Drugs and injection procedures}

Cocaine $\mathrm{HCl}$ (Qinhai Pharmaceutical) was dissolved in sterile saline and was injected $5 \mathrm{~min}$ before the CPP training (or test, experiment 5) sessions. Based on the work of Fischer et al. (2002, 2003a), we used $\beta$-butyrolactone at a dose of $100 \mathrm{ng} /$ side to inhibit Cdk5 activity. $\beta$-Butyrolactone (BIOMOL) was dissolved in $0.2 \%$ DMSO (vehicle) and was prepared in stock solutions of $200 \mathrm{ng} / \mu \mathrm{l}$. $\beta$-Butyrolactone was injected with Hamilton syringes connected to 30 gauge injectors (Plastics One). The infusion volume was $0.5 \mu \mathrm{l}$, and the drug was injected bilaterally over $1 \mathrm{~min}$; the injection needle was kept in place for an additional $1 \mathrm{~min}$ to allow for drug diffusion (Lu et al., 2005). In experiments that did not involve Western blots, the rats were anesthetized with sodium pentobarbital ( $100 \mathrm{mg} / \mathrm{kg}$, i.p.) and transcardially perfused. Cannula placements were assessed using Nissl staining with thickness of $40 \mu \mathrm{m}$ under light microscopy. Seventeen subjects with misplaced cannulae were excluded. The locations of cannula tips of the rats are shown in Figure 7.

\section{Conditioned place preference}

$\mathrm{CPP}$ was performed using an unbiased, counterbalanced protocol (Wang et al., 2008). The CPP apparatus consisted of five identical three-chamber polyvinylchloride (PVC) boxes ( $\mathrm{Li}$ et al., 2008; Wang et al., 2008). Two large side chambers $(27.9 \mathrm{~cm}$ long $\times 21.0 \mathrm{~cm}$ wide $\times 20.9 \mathrm{~cm}$ high) were separated by a smaller one $(12.1 \mathrm{~cm}$ long $\times 21.0 \mathrm{~cm}$ wide $\times 20.9 \mathrm{~cm}$ high with a smooth PVC floor). The two larger chambers differed in their floor texture (bar or grid, respectively) and provided distinct contexts that were paired with cocaine or saline injections. Three distinct chambers were separated by manual guillotine doors.

Baseline preference was assessed by placing the rats in the center compartment of the CPP apparatus and allowing ad libitum access to all compartments for $15 \mathrm{~min}$. Thirteen of the initial 245 rats were excluded because of a strong unconditioned preference ( $>540 \mathrm{~s})$. On subsequent conditioning days, the rats were trained for 8 consecutive days with alternating injections of cocaine $(10 \mathrm{mg} / \mathrm{kg}$, i.p.) or saline $(1 \mathrm{ml} / \mathrm{kg}$, i.p.) or saline in both compartments. After each injection, the rats were confined to the corresponding conditioning chambers for $45 \mathrm{~min}$ and then returned to their home cages. Tests for the expression of cocaine CPP in a drug-free state (15 min duration) were performed at different days after training (see below). The procedure during testing was same as during the initial baseline preference assessment. The CPP score was defined as the time (in seconds) spent in the cocaine-paired chamber minus the time spent in the saline-paired chamber during CPP testing.

\section{Tissue sample preparation}

In experiments in which Cdk5 activity and Cdk5 and p35 levels were determined, the rats were decapitated without anesthesia $2 \mathrm{~h}$ after the end of the $15 \mathrm{~min}$ CPP tests. After decapitation, the brains were rapidly extracted and frozen in $-60^{\circ} \mathrm{C} \mathrm{N}$-hexane. The brains were then transferred to a $-80^{\circ} \mathrm{C}$ freezer. We used a freezing cryostat $\left(-20^{\circ} \mathrm{C}\right)$ to make $1-\mathrm{mm}-$ thick coronal sections located approximately $-2.5-3.0 \mathrm{~mm}$ from bregma. Bilateral tissue punches (16 gauge) of the CeA and BLA were then taken and pooled together. Tissue punches were homogenized (three times 10-15 s; $5 \mathrm{~s}$ interval) with an electrical disperser (Wiggenhauser, Sdn Bhd) after $30 \mathrm{~min}$ in RIPA lysis buffer (Beyotime Biotechnology; 20 mм Tris, pH 7.5, $150 \mathrm{~mm} \mathrm{NaCl,} \mathrm{1 \%} \mathrm{Triton} \mathrm{X-100,} 2.5 \mathrm{~mm}$ sodium pyrophosphate, $1 \mathrm{~mm}$ EDTA, $1 \% \mathrm{Na}_{3} \mathrm{VO}_{4}, 0.5 \mu \mathrm{g} / \mathrm{ml}$ leupeptin, $1 \mathrm{~mm}$ phenylmethanesulfonyl fluoride). The tissue homogenates were then subjected to $12,000 \times g$ centrifugation at $4^{\circ} \mathrm{C}$ for $8 \mathrm{~min}$. The above procedures were performed at 0 to $4^{\circ} \mathrm{C}$. The protein concentrations of all samples were determined using the bicinchoninic acid assay (Beyotime Biotechnology). Samples were further diluted in RIPA lysis buffer to equalize the protein concentrations.

\section{Western blot assays}

The procedures of the assay were based on those used in our previous studies (Lu et al., 2005; Li et al., 2008). Four times loading buffer (16\% glycerol, $20 \%$ mercaptoethanol, $2 \%$ SDS, $0.05 \%$ bromophenol blue) was added to each sample (3:1; sample/loading buffer) before boiling for 3 min. Samples were cooled and subjected to SDS-PAGE (10\% acrylamide/ $0.27 \% \mathrm{~N}, N^{\prime}$-methylenebisacryalamide resolving gel) for $\sim 40 \mathrm{~min}$ at 80 $\mathrm{V}$ in stacking gel and $\sim 1 \mathrm{~h}$ at $130 \mathrm{~V}$ in resolving gel. Proteins were transferred electrophoretically to Immobilon-P transfer membranes (Millipore) at $0.25 \mathrm{~A}$ for $2.5 \mathrm{~h}$. Membranes were washed with TBST (Tris-buffered saline plus $0.05 \%$ Tween 20, pH 7.4) and then dipped in blocking buffer [ $5 \%$ bovine serum albumin (BSA) in TBST] overnight at $4^{\circ} \mathrm{C}$. The next day, the membranes were incubated for $1 \mathrm{~h}$ at room temperature on an orbital shaker with anti-Cdk5 antibody (1:1000; Santa Cruz Biotechnology), anti-p35 antibody (1:500; Santa Cruz), and $\beta$-actin (1:1000; Santa Cruz) in TBST plus $5 \%$ BSA and $0.05 \%$ sodium azide. After three $5 \mathrm{~min}$ washes (three times) in TBST buffer, the blots were incubated for $45 \mathrm{~min}$ at room temperature on a shaker with horseradish peroxidase-conjugated secondary antibody (p35 was goat anti-rabbit IgG, and Cdk5 was goat anti-mice; Santa Cruz; PI-1000; Vector Laboratories) diluted 1:5000 in blocking buffer. The blots were then washed three times for $5 \mathrm{~min}$ each in TBST and incubated with a layer of Super Signal Enhanced chemiluminescence substrate (Detection Reagents 1 and 2; 1:1 ratio; Pierce Biotechnology) for $1 \mathrm{~min}$ at room temperature. Excess mixture was dripped off before the blots were wrapped with a clean piece of plastic wrap (no bubbles between blot and wrap), and then the blots were exposed to x-ray film (Eastman Kodak) for 5-60 s. Values 
for $\mathrm{p} 35$ and $\mathrm{Cdk} 5$ protein levels were normalized to $\beta$-actin and analyzed with Quantity One software (version 4.4.0; Bio-Rad). The Western blot assays also included the brains of 12 naive rats that did not participate in the behavioral experiments. The values of the Cdk5 and p35 levels of these rats, which were pooled and run as a single blot, were used as a reference point in the graphical presentation of the data.

\section{Cdk5 activity assay}

Cdk5 activity was determined by radioactivity, and the procedures of the assay were based on previous studies (Chen and Chen, 2005). Tissues from the amygdala were lysed in RIPA buffer. Cdk5 was immunoprecipitated from the amygdala homogenates using an anti-Cdk5 antibody (Santa Cruz Biotechnology) overnight at $4^{\circ} \mathrm{C}$. Immobilized protein A resin slurry (Pierce Biotechnology) was added to the antigen-antibody complex, and the reaction was incubated with gentle mixing for $2 \mathrm{~h}$ at room temperature. Afterward, $0.5 \mathrm{ml}$ of immunoprecipitation buffer $(25$ $\mathrm{mm}$ Tris, $150 \mathrm{~mm} \mathrm{NaCl}, \mathrm{pH}$ 7.2) was added to the immunoprecipitated samples and centrifuged for $2-3 \mathrm{~min}$ at $2500 \times \mathrm{g}$. The supernatant was discarded. This step was repeated several times. The final immunoprecipitated samples were suspended and incubated with $0.08 \mu \mathrm{g} / \mu$ l histone $\mathrm{H} 1$ protein (H5505; Sigma-Aldrich) in $50 \mu \mathrm{l}$ of kinase assay buffer (10 $\mathrm{mm} \mathrm{MgCl}_{2}, 1 \mathrm{~mm}$ DTT, $50 \mu \mathrm{M}$ ATP, $0.1 \mu \mathrm{Ci} / \mu \mathrm{l}\left[\gamma^{-}{ }^{32} \mathrm{P}\right]$ adenosine triphosphate) at $30^{\circ} \mathrm{C}$ for $30 \mathrm{~min}$. The reaction was terminated by spotting $20 \mu \mathrm{l}$ of the reaction mixture on a P81 phosphocellulose disc (Whatman P81; Millipore). The discs were washed three times (5 min each) with $0.75 \%$ phosphoric acid, followed by soaking in $95 \%$ ethanol for 10 min and dried in the air. Radioactivity was measured with a scintillation counter (Beijing Normal University, Beijing, China) and corrected for basal activity.

\section{Experiments}

Experiment 1: effect of cocaine CPP on BLA and CeA Cdk5 activity, and $C d k 5$ and $p 35$ protein levels. We used four groups of rats $(n=10-15$ per group) to assess the effect of tests for the expression of cocaine CPP on $\mathrm{Cdk} 5$ activity, Cdk5 and $\mathrm{p} 35$ protein levels in the BLA and CeA (see Fig. $1 A$ ). All rats underwent a baseline preference test. Subsequently, the two groups of saline-injected rats received daily saline injections over $8 \mathrm{~d}$ in either their home cage or the $\mathrm{CPP}$ apparatus, whereas the two groups of cocaine-injected rats received daily injections of saline (four times) or cocaine (four times) in either their home cage or the CPP apparatus. The test for the expression of cocaine CPP was performed $1 \mathrm{~d}$ after the last training/injection day for all rats. Two hours after the end of the $15 \mathrm{~min}$ CPP test, the rats were decapitated, and their brains were removed for subsequent determination of Cdk5 activity, and $\mathrm{p} 35$ and Cdk5 protein levels in the BLA and CeA. The home cage injection-exposed rats were decapitated at the same time as the CPP-trained rats. The dependent measures were the CPP score, Cdk5 activity in the BLA and CeA, and p35 and Cdk5 protein levels in the BLA and CeA. In each experimental condition, approximately one-half of the rats (5-7/group) were used for Western blots and the other one-half (5-8/group) were used for kinase assay.

Experiment 2: effect of inhibition of BLA Cdk5 on consolidation of cocaine $C P P$. We used six groups of rats to determine the role of BLA Cdk5 in consolidation of cocaine CPP (see Fig. 2 A). For this purpose, we used a classical memory consolidation approach in which a drug is injected either immediately or several hours after the acquisition of the learning task and the expression of the learned task is assessed in a drug-free test on a different day. The effect of the drug on memory consolidation is inferred if it disrupts learning when given immediately but not several hours later after the training sessions (McGaugh, 2000). Four groups of rats ( $n=7-9$ per group) were injected with either vehicle or $\beta$-butyrolactone into the BLA or CeA immediately ( $0 \mathrm{~min})$ after the four cocaine-context pairing training sessions; no injections were given after the saline-context pairing training sessions. Two other groups $(n=7-10$ per group) were injected into the BLA with vehicle or $\beta$-butyrolactone $6 \mathrm{~h}$ after each of the cocaine training sessions. In all groups, the test for the expression of cocaine CPP was performed $1 \mathrm{~d}$ after the last training day. Two hours after the end of CPP test, the rats receiving injection of $\beta$-butyrolactone or vehicle immediately after the cocaine training ses- sions were decapitated, and their brains were removed for subsequent determination of p35 levels in the BLA and CeA using Western blotting.

Experiment 3: effect of acute inhibition of BLA Cdk5 on the expression of cocaine $C P P$. We used four groups of rats ( $n=7-9$ per group) to determine the role of BLA Cdk5 in the acute expression of learned cocaine CPP (see Fig. 3A). The rats were trained for cocaine CPP over $8 \mathrm{~d}$ and tested for the expression of CPP on day 9 without any injections (test 1 ). On day 10, the rats were injected with either vehicle or $\beta$-butyrolactone into the BLA or CeA immediately before another CPP test (test 2). On day 11 , the rats were tested again (test 3 ) for cocaine CPP without any injections. Two hours after the end of test 3 , all rats were decapitated, and their brains were removed for subsequent determination of p35 levels in the BLA and CeA using Western blotting.

Experiment 4: effect of inhibition of BLA Cdk5 on reconsolidation of learned cocaine $C P P$. We used eight groups of rats to determine the role of BLA Cdk5 in reconsolidation of learned cocaine CPP (see Figs. 4A, 5A). All rats were trained for cocaine CPP over $8 \mathrm{~d}$ and tested for the expression of CPP on day 9 without any injections (test 1 ). On day 10, four groups of rats $(n=8-10$ per group) were confined to the cocaine-paired context for $10 \mathrm{~min}$ to reactivate cocaine rewarding memory (Wang et al., 2008) and were then injected with either vehicle or $\beta$-butyrolactone into the BLA or CeA immediately ( $0 \mathrm{~min}$ ) after cocaine-context exposure. On day 11 , these rats were tested again (test 3 ) for cocaine CPP without any injections. Four other groups of BLA-injected rats underwent an identical experimental procedure, but on day 10 they were injected with vehicle or $\beta$-butyrolactone either $6 \mathrm{~h}$ after the cocaine-context exposure session (two groups; $n=7-10$ per group) or without any context exposure (two groups; $n=7-10$ per group).

Experiment 5: additional characterization of the effect of inhibition of $B L A C d k 5$ on reconsolidation of learned cocaine CPP. We used two groups of rats ( $n=8-10$ per group) to determine the persistence of the effect of BLA $\beta$-butyrolaxtone injections on reconsolidation of learned cocaine CPP (see Fig. 6A). The rats were trained for cocaine CPP over $8 \mathrm{~d}$ and tested for the expression of CPP on day 9 without any injections (test 1 ). On day 10 , the rats were confined to the cocaine-paired context for 10 min to reactivate the cocaine rewarding memory and then injected with either vehicle or $\beta$-butyrolactone into the BLA immediately ( 0 min) after cocaine-context exposure. On days 11 and 25, these rats were tested again (test 2 and test 3 ) for cocaine CPP without any injections. On day 26 , all rats were given a priming injection of cocaine $(10 \mathrm{mg} / \mathrm{kg}$, i.p.) and tested again for cocaine CPP. Cocaine was injected immediately before the test session.

\section{Data analysis}

Data are expressed as mean \pm SEM and were analyzed by ANOVA with the appropriate between- and within-subjects factors for the different experiments (see Results). The kinase assay and Western blot data were analyzed separately for the BLA and CeA. Significant main effects and interactions $(p<0.05)$ from the factorial ANOVAs were followed by simple ANOVA and Tukey's post hoc tests. Because our multifactorial ANOVAs yielded multiple main effects and interaction effects, we only report in Results significant effects that are critical for data interpretation. Additionally, for clarity, post hoc analyses are indicated by asterisks in the figures but are not described in Results.

\section{Results}

\section{Experiment 1: effect of cocaine CPP on BLA and CeA Cdk5 activity, Cdk5 and p35 protein levels}

The expression of cocaine CPP (Fig. $1 B$ ) was associated with increased Cdk5 activity (Fig. $1 C, D$ ) and increased protein levels of p35 in the BLA but not CeA (Fig. $1 E, F$ ). The analysis of the behavioral data of the expression of cocaine CPP included the between-subject factors of drug (saline, cocaine) and context (home cage, CPP apparatus), and the within-subject factor of test phase (pretraining baseline preference, posttraining CPP test). This analysis revealed a significant drug by context by test phase interaction $\left(F_{(1,56)}=13.14 ; p<0.01\right)$, training by conditioning interaction $\left(F_{(1,56)}=8.57 ; p<0.01\right)$. These interactions are at- 
tributable to the fact that cocaine CPP was only observed in the group of rats injected with cocaine in the CPP apparatus. The analyses of Cdk5 activity and the Western blots data included the between-subject factors of drug (saline, cocaine) and context (home cage, CPP apparatus). The analyses for Cdk5 activity in the BLA revealed a significant drug by context interaction $\left(F_{(1,23)}=7.34 ; p<0.05\right)$. No significant effects were observed for Cdk5 activity in the CeA (values of $p>0.1$ ). The analyses for $\mathrm{p} 35$ levels in the BLA revealed a significant drug by context interaction $\left(F_{(1,23)}=19.69 ; p<0.01\right)$. No significant effects were observed for Cdk5 levels in the BLA or Cdk5 or p35 levels in the CeA (values of $p>0.1$ ). No group differences were observed for $\beta$-actin levels, as assessed by Western blots (data not shown). Post hoc group differences are indicated in Figure 1.

\section{Experiment 2: effect of inhibition of BLA Cdk 5 on consolidation of cocaine CPP}

$\beta$-Butyrolactone injections into the BLA immediately after exposure to the cocaine-paired context during CPP training impaired the subsequent expression of cocaine CPP in a drug-free state (Fig. $2 \mathrm{~B}$, left column) and led to decreased BLA p35 levels (Fig. 2D); these data indicate a role of BLA Cdk5 in consolidation of the memories for the cocaine-paired context. $\beta$-Butyrolactone injections into the BLA $6 \mathrm{~h}$ after the training sessions (Fig. $2 B$, right column) or into the $\mathrm{CeA}$ immediately after the training session (Fig. 2C) were ineffective. The statistical analyses of CPP scores after BLA posttraining sessions immediate injections included the between-subject factor of $\beta$-butyrolactone $(0,100 \mathrm{ng} / \mathrm{side})$ and the withinsubject factor of test phase (pretraining baseline preference, posttraining CPP test). This analysis revealed a significant $\beta$-butyrolactone by test phase interaction $\left(F_{(1,14)}=8.93 ; p<0.05\right)$. The analyses of the effect of BLA $\beta$-butyrolactone injections $6 \mathrm{~h}$ after the training sessions or $\mathrm{CeA}$ $\beta$-butyrolactone injections immediately after the training sessions revealed significant effects of test phase $\left(F_{(1,12)}=56.67\right.$, $p<0.01$, and $F_{(1,14)}=46.42, p<0.01$, respectively) but not of $\beta$-butyrolactone or $\beta$-butyrolactone by test phase interaction (values of $p>0.1$ ). The analyses of $\mathrm{p} 35$ levels in the groups that received injections of $\beta$-butyrolactone or vehicle after the cocaine training sessions revealed a significant effect of $\beta$-butyrolactone in BLA $\left(F_{(1,11)}=23.52 ; p<0.01\right)$ but not CeA $(p>0.1)$ (Fig. $2 D)$. No group differences were observed for $\beta$-actin levels (data not shown). Post hoc group differences are indicated in Figure 2.
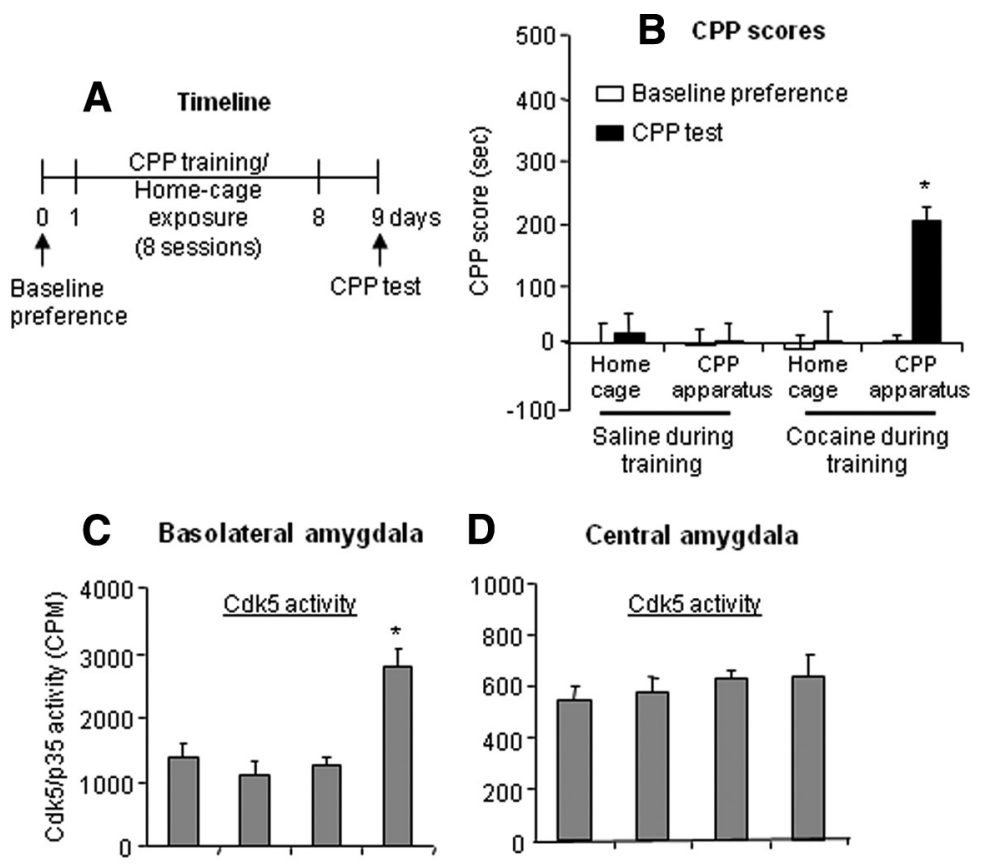

D Central amygdala
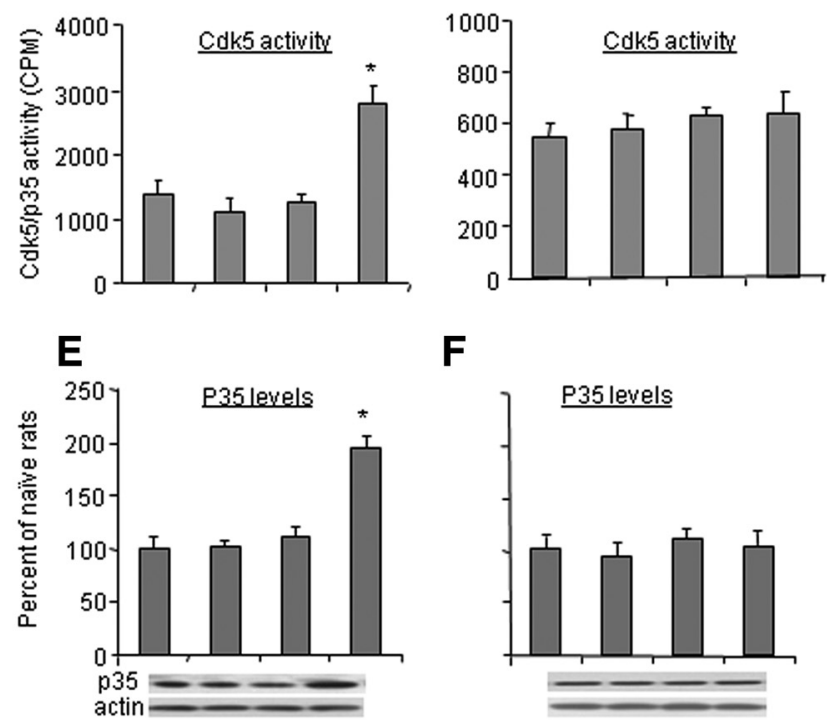

F
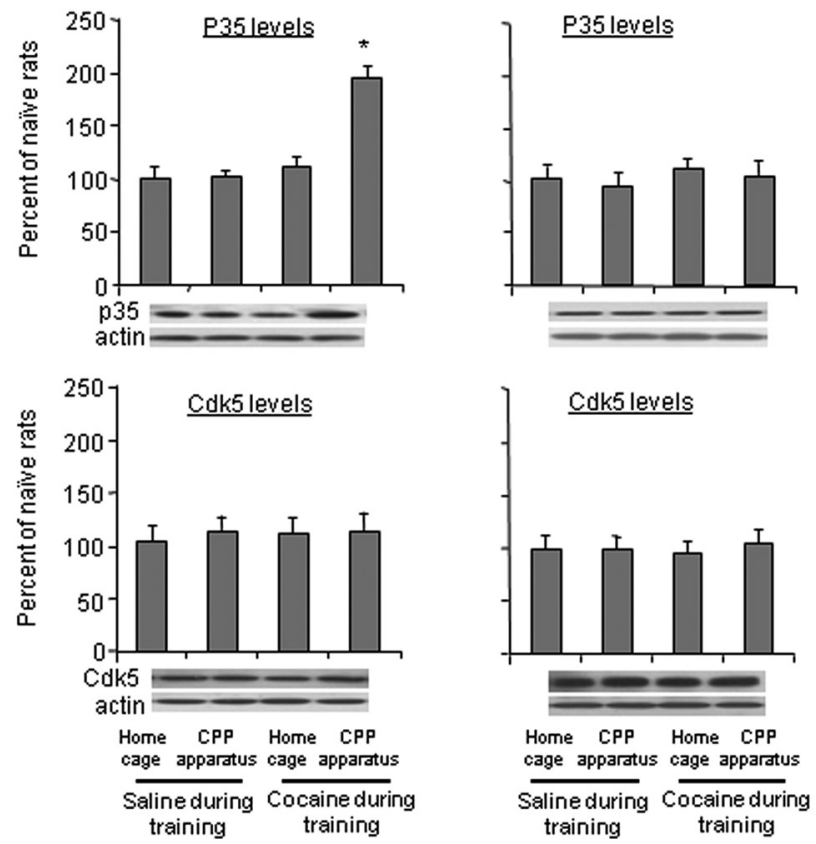

Figure 1. The expression of cocaine CPP is associated with increased $C \mathrm{dk} 5$ activity and $\mathrm{p} 35$ protein levels but not $\mathrm{Cdk} 5$ protein levels in the BLA but notCeA. $A$, Timeline of the experiment (see Materials and Methods for the experimental conditions of the $4 \mathrm{groups}$ ). $\boldsymbol{B}$, Mean \pm SEM. CPP scores (time in the cocaine-paired minus time in the saline-paired side) during baseline preference and during a test for the expression of cocaine CPP 1 d after training. *Different from the other experimental groups, $p<0.05, n=10-15$ per group. C, $D, C d k 5$ activity in the BLA and CeA; Cdk5 activity is expressed as specific counts (counts per minute). * Different from the other experimental groups, $p<0.05, n=5-7$ per group. $E, F$, p35 and Cdk5 levels in the BLA and CeA; 335 and Cdk5 levels are presented as a percentage (mean \pm SEM) of values of naive control rats $(n=5)$. *Different from the other experimental groups, $p<0.05, n=5-8$ per group.

\section{Experiment 3: effect of acute inhibition of BLA Cdk5 on the expression of cocaine CPP}

BLA but not CeA $\beta$-butyrolactone injections inhibited the expression of cocaine CPP when injected immediately before test 2 (Fig. $3 B, C$ ). BLA injections also inhibited CPP expression and the associated increase in p35 levels on test 3 conducted $1 \mathrm{~d}$ later (Fig. 3D). The CPP score data after BLA injections were analyzed with a mixed ANOVA that included 
A
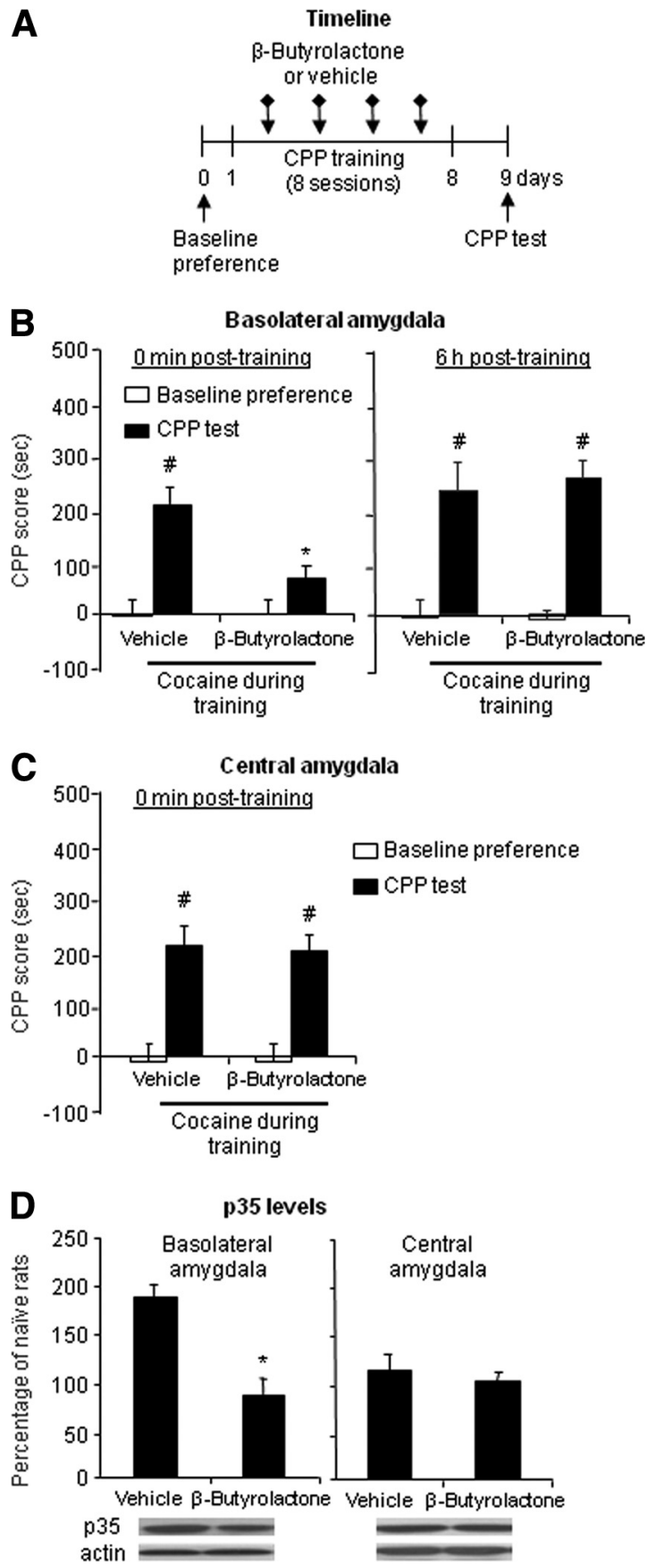

Figure 2. Inhibition of $\mathrm{Cdk} 5$ in the BLA but not CeA prevents the consolidation of cocaine CPP. $A$, Timeline of the experiment. $\boldsymbol{B}, \boldsymbol{C}$, Mean \pm SEM. CPP scores during baseline preference and during a test for the expression of cocaine CPP $1 \mathrm{~d}$ after training in rats injected with vehicle $(0.5 \mu \mathrm{l} /$ side) or $\beta$-butyrolactone $(100 \mathrm{ng} / \mathrm{side})$ into the BLA or CeA immediately after ( $0 \mathrm{~min})$ or into the BLA 6 h after cocaine - context pairings ( 4 sessions) during (PP training. * Different from vehicle, $p<0.05$. "Different from baseline, $p<0.05, n=7-10$ per group. $\boldsymbol{D}, \mathrm{p} 35$ levels in the $B L A$ and $C e A$ in rats injected with vehicle or $\beta$-butyrolactone into the BLA or CeA immediately after the cocaine- context pairings during CPP training. *Different from vehicle, $p<0.05, n=$ $5-7$ per group.

the between-subjects factor of $\beta$-butyrolactone and the within-subjects factor of test phase (baseline preference, test 1 , test 2 , and test 3$)$. Analysis revealed significant effects of $\beta$-butyrolactone $\left(F_{(1,14)}=18.80 ; p<0.01\right)$, test phase $\left(F_{(3,42)}=\right.$ 13.96; $p<0.01)$, and $\beta$-butyrolactone by test phase interaction $\left(F_{(3,42)}=6.13 ; p<0.01\right)$. Post hoc analysis revealed that $\beta$-butyrolaxtone-treated rats exhibited significantly decreased
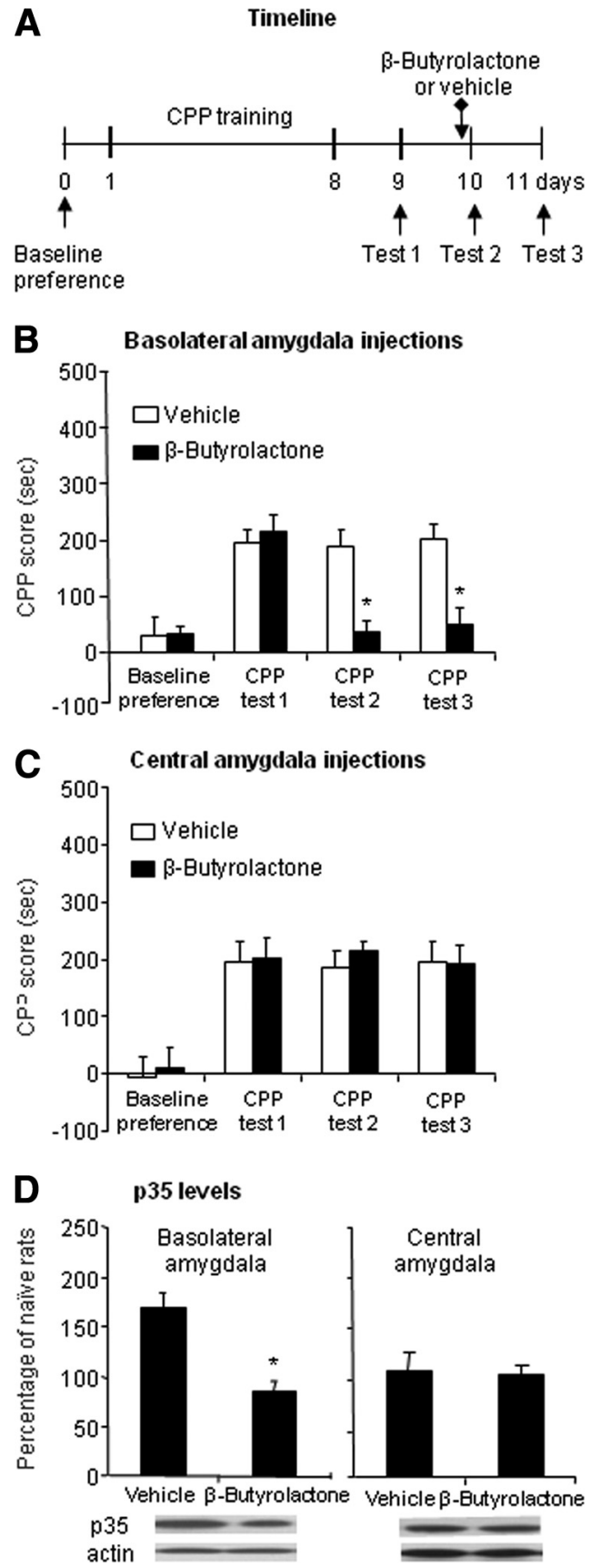

Figure 3. Inhibition of $C \mathrm{dk} 5$ in the BLA but not CeA prevents the expression of cocaine CPP. $A$, Timeline of the experiment. $B, C$, Mean \pm SEM. CPP scores during baseline preference and during tests for the expression of cocaine (PP in rats injected vehicle $(0.5 \mu \mathrm{l} / \mathrm{side})$ or $\beta$-butyrolactone ( $100 \mathrm{ng} / \mathrm{side}$ ) into the BLA or CeA immediately before test 2. * Different from vehicle, $p<0.05, n=7-9$ per group. $\boldsymbol{D}, \mathrm{p} 35$ levels in the BLA and CeA after test $3 .{ }^{*}$ Different from vehicle, $p<0.05, n=5-7$ per group.

CPP score on CPP test $2(p<0.01)$ compared with vehicletreated rats (Fig. 3B). A similar analysis after CeA injections revealed a significant main effect of test phase $\left(F_{(2,28)}=35.31\right.$; $p<0.01)$ but not a main effect of $\beta$-butyrolactone or interaction between the two factors (values of $p>0.1$ ) (Fig. $3 C$ ). The analyses of p35 levels after test 3 revealed a significant effect of BLA $\beta$-butyrolactone injections $\left(F_{(1,11)}=18.25 ; p<0.01\right)$ (Fig. 3D) but not CeA injections $(p>0.05)$. Post hoc group differences are indicated in Figure 3. 
A
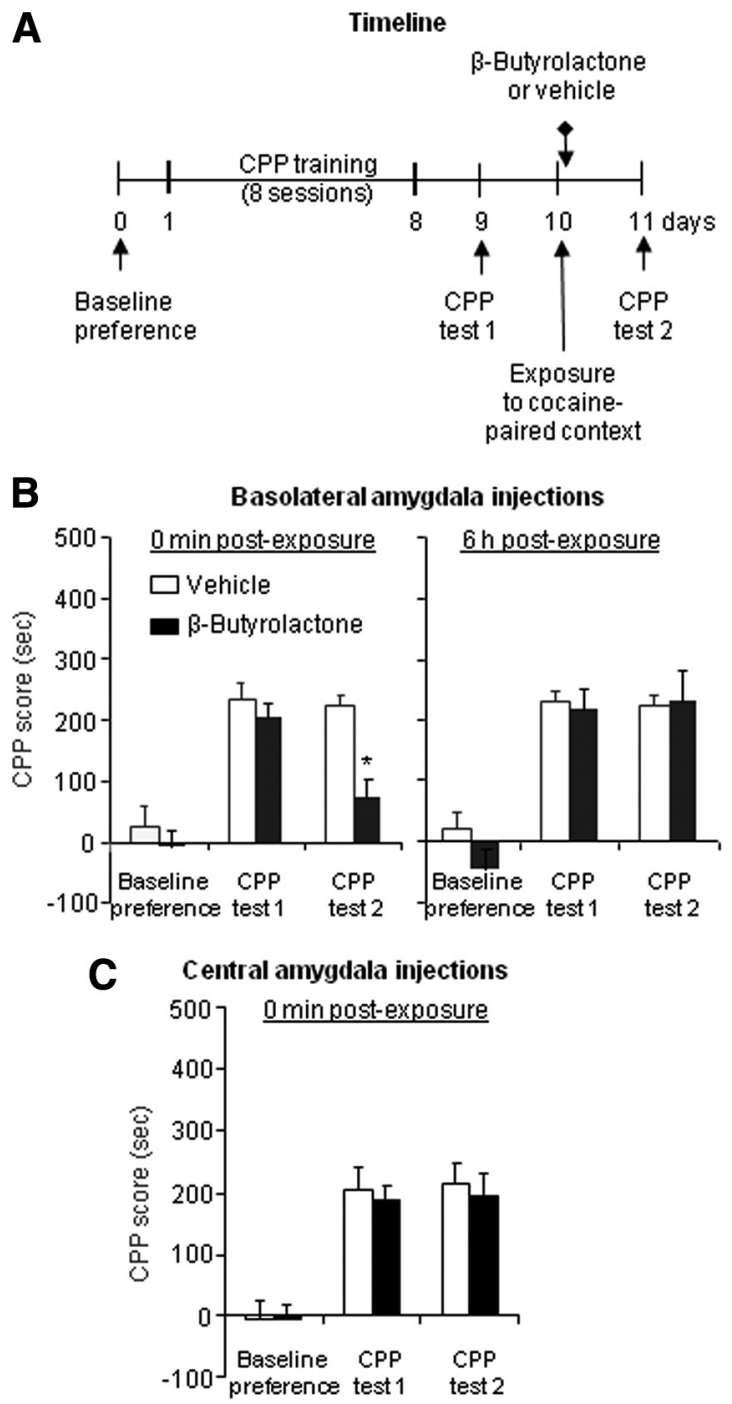

Figure 4. Inhibition of $\mathrm{Cdk} 5$ in the BLA but not CeA prevents the reconsolidation of cocaine CPP. $A$, Timeline of the experiment. $B, C$, Mean \pm SEM. CPP scores during baseline preference and during tests for the expression of cocaine (PP in rats injected with vehicle $(0.5 \mu \mathrm{l} / \mathrm{side})$ or $\beta$-butyrolactone ( $100 \mathrm{ng} / \mathrm{side})$ into the BLA or CeA immediately after $(0 \mathrm{~min})$ exposure to the cocaine-paired context on day 10 or into the BLA $6 \mathrm{~h}$ after context exposure. *Different from vehicle, $p<0.05, n=7-10$ per group.

\section{Experiment 4: effect of inhibition of BLA Cdk5 on reconsolidation of learned cocaine $\mathrm{CPP}$}

BLA but not CeA $\beta$-butyrolactone injections inhibited the expression of cocaine CPP on day 11 when injected immediately after exposure to the cocaine-paired context on day 10; BLA $\beta$-butyrolactone injections were ineffective when injected $6 \mathrm{~h}$ after cocaine-context exposure or without context exposure (Figs. 4, 5). These data indicate a role of Cdk5 activity in BLA in reconsolidation of learned cocaine $\mathrm{CPP}$. The CPP score data for immediate BLA injections were analyzed with a mixed ANOVA that included the between-subjects factor of $\beta$-butyrolactone and the within-subjects factor of test phase (baseline preference, test 1, and test 2) (Fig. 4B, left column). This analysis revealed a significant interaction between these two factors $\left(F_{(2,30)}=3.85\right.$; $p<0.05$ ). The analyses of delayed ( $6 \mathrm{~h}$ ) BLA injections (Fig. $4 B$, right column), immediate CeA injections (Fig. $4 C$ ), or BLA injections without context exposure (Fig. $5 B$ ) revealed a significant main effect test phase $\left(F_{(2,28)}=56.67, p<0.01 ; F_{(2,28)}=35.31\right.$, $p<0.01$; or $F_{(2,28)}=21.01, p<0.01$, respectively) but not a main

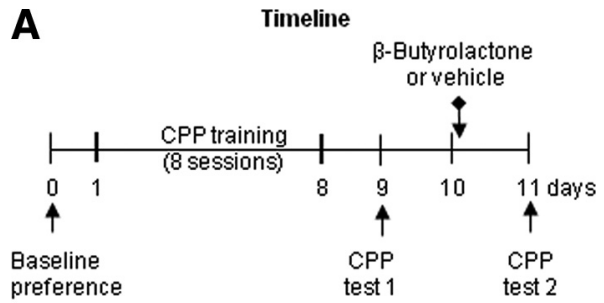

B

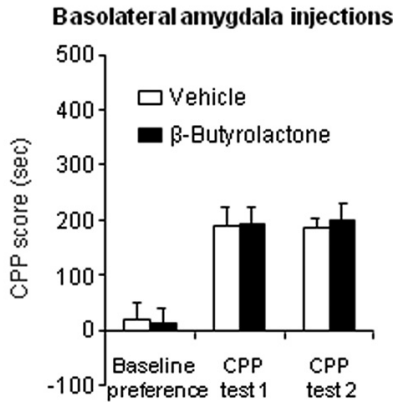

Figure 5. Inhibition of $C d k 5$ in the BLA has no effect on reconsolidation of cocaine CPP when rats are not exposed to the cocaine-paired context before $\beta$-butyrolactone injections. $A$, Timeline of the experiment. $\boldsymbol{B}$, Mean \pm SEM. CPP scores during baseline preference and during tests for the expression of cocaine (PP in rats injected with vehicle $(0.5 \mu \mathrm{l} / \mathrm{side})$ or $\beta$-butyrolactone ( $100 \mathrm{ng} / \mathrm{side})$ into the BLA on day 10 without exposure to the cocaine-paired context $(n=7-10$ per group).

effect of $\beta$-butyrolactone or interaction between the two factors (values of $p>0.1$ ). Post hoc group differences are indicated in Figures 4 and 5.

\section{Experiment 5: additional characterization of the effect of inhibition of BLA Cdk5 on reconsolidation of learned cocaine CPP}

BLA $\beta$-butyrolactone injections inhibited the expression of cocaine CPP on days 11 and 25 when injected immediately after exposure to the cocaine-paired context on day 10; the inhibitory effect of these injections on the expression of cocaine CPP was not reversed by acute priming injections of cocaine on day 26 (Fig. 6). These data indicate that the disruption of reconsolidation of learned cocaine CPP by BLA $\beta$-butyrolactone injections persists for at least 2 weeks and is not reversed by acute reexposure to cocaine. The data for the CPP score in the cocaine-free state were analyzed with a mixed ANOVA that included the betweensubjects factor of $\beta$-butyrolactone and the within-subjects factor of test phase (baseline preference, test 1 , test 2 , and test 3 ). The ANOVA revealed significant differences in CPP scores for $\beta$-butyrolactone $\left(F_{(1,14)}=11.03 ; p<0.01\right)$, test phase $\left(F_{(3,42)}=\right.$ $16.62 ; p<0.01)$, and a $\beta$-butyrolactone by test phase interaction $\left(F_{(3,42)}=25.73 ; p<0.01\right)$. CPP did not recover in the group receiving microinjections of $\beta$-butyrolaxtone into the BLA before reexposure to the previous training chambers. The data for the CPP score after cocaine priming were analyzed with a mixed ANOVA that included the between-subjects factor of $\beta$-butyrolactone and the within-subjects factor of test phase [test 3 (no priming), cocaine priming test]. This analysis revealed a significant effect of $\beta$-butyrolactone $\left(F_{(1,14)}=29.66 ; p<0.01\right)$, but not of test phase or an interaction between the two factors (values of $p>$ 0.1). Post hoc group differences are indicated in Figure 6.

\section{Discussion}

We studied the role of amygdala Cdk5 in the memories of cocaine-associated environmental cues, as assessed in the CPP 

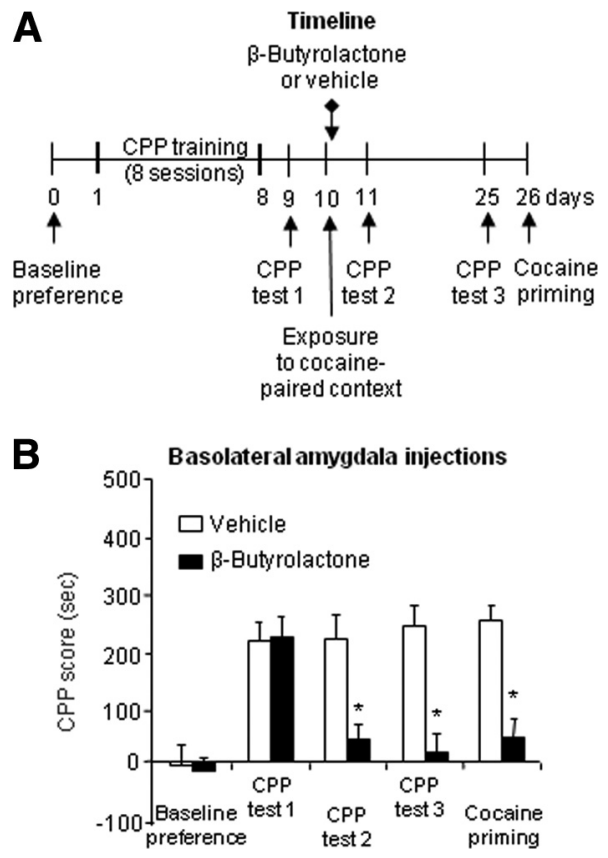

Figure 6. Additional characterization of inhibition of $C \mathrm{dk} 5$ in the BLA on reconsolidation of cocaine CPP. $\boldsymbol{A}$, Timeline of the experiment. $\boldsymbol{B}$, Mean \pm SEM. CPP scores during baseline preference and during tests for the expression of cocaine CPP in rats injected with vehicle $(0.5$ $\mu \mathrm{l} /$ side) or $\beta$-butyrolactone ( $100 \mathrm{ng} / \mathrm{side}$ ) into the BLA or CeA immediately after ( $0 \mathrm{~min}$ ) exposure to the cocaine-paired context on day 10 . Five minutes before the last CPP test (termed cocaine priming in $\boldsymbol{A})$, the rats were injected with cocaine $\left(10 \mathrm{mg} / \mathrm{kg}\right.$, i.p.). ${ }^{*}$ Different from vehicle, $p<0.05, n=8-10$ per group.

procedure. We found that the expression of cocaine CPP was associated with increased Cdk5 activity in the BLA of drug-free rats previously exposed to four cocaine injections in one context and four saline injections in a different context. The increased Cdk5 activity in the BLA was associated with increased p35 protein levels but not Cdk5 protein, an observation consistent with the notion that $\mathrm{p} 35$ is the rate-limiting factor for Cdk5 activity (Takahashi et al., 2005). Additionally, posttraining sessions inhibition of Cdk5 activity in the BLA impaired the subsequent expression of cocaine CPP and the subsequent increase in BLA p35 levels during cocaine CPP testing. These data indicate a role of Cdk5 in consolidation of cocaine cue memories. Furthermore, pretest inhibition of Cdk5 activity in the BLA abolished the expression of cocaine CPP in tests conducted immediately after $\beta$-butyrolactone injections and $1 \mathrm{~d}$ later; this inhibitory effect was associated with decreased p35 levels in BLA. The acute effect of $\beta$-butyrolactone suggests a role of Cdk 5 activity in either retrieval of cocaine cue memories or the incentive motivational effect of cocaine cues (see below); the delayed effect of $\beta$-butyrolactone suggests a role of Cdk5 activity in reconsolidation of cocaine cue memories. This latter hypothesis was confirmed by the finding that acute posttest inhibition of Cdk5 activity in the BLA abolished the subsequent expression of cocaine CPP for up to $14 \mathrm{~d}$ after the test sessions; this effect was not reversed by a priming injection of cocaine.

The effects of our experimental manipulations in the BLA were anatomically and temporally specific (Fig. 7). First, the expression of cocaine CPP was not associated with changes in Cdk5 activity and levels in the CeA. Second, inhibition of Cdk5 activity in the CeA had no effect on cocaine CPP. Third, inhibition of $\mathrm{Cdk} 5$ activity in the BLA $6 \mathrm{~h}$ after the training or the test sessions had no effect on cocaine CPP. Fourth, inhibition of Cdk 5 activity
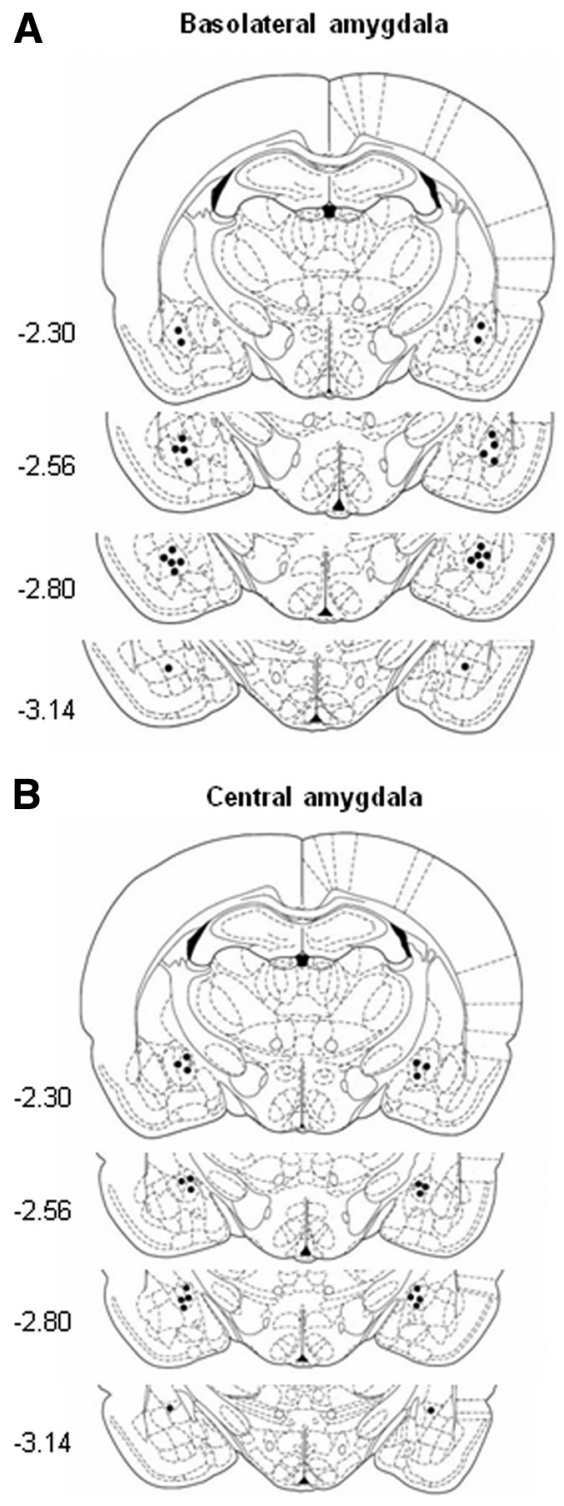

Figure 7. Schematic representation of injection sites in the basolateral amygdala $(\boldsymbol{A})$ and the central amygdala $(\boldsymbol{B})$.

in the BLA in the absence of cocaine context exposure had no effect on cocaine CPP. Additionally, the effects of $\beta$-butyrolaxtone BLA injections on cocaine cue memories are not attributable to competition between cocaine rewarding effects and potential aversive effects of these injections. We found in a pilot study that neither place version nor place preference was developed when four $\beta$-butyrolaxtone BLA injections were paired with one context and no injections with a different context (our unpublished observations).

Together, our data indicate that Cdk5 activity in the BLA is critical for the consolidation and reconsolidation of cocaine cue memories in the CPP procedure. Additionally, the finding that acute pretest BLA $\beta$-butyrolactone injections inhibited the expression of learned cocaine CPP may also suggest a role of Cdk5 in BLA in retrieval of cocaine cue memories. However, an alternative account of these data is that, when the $\beta$-butyrolactone was injected into the BLA immediately before the tests for the expression of cocaine CPP, the drug acutely inhibited the incentive motivational effects of the cocaine cues without interfering with memory retrieval. 


\section{Role of Cdk5 in learning and memory}

Our data extend previous work of Fischer et al. (2003b) on the role of Cdk5 in learning and memory. These investigators identified a critical role of Cdk 5 activity in the septo-hippocampal system in consolidation (Fischer et al., 2002, 2003b) and extinction (Sananbenesi et al., 2007) of conditioned fear memories. Fischer et al. (2005) also reported that an inducible transgenic manipulation that transiently increases $\mathrm{Cdk} 5$ activity in the hippocampus enhances long-term potentiation and facilitates hippocampus-dependent spatial learning, as assessed in a water maze task (Fischer et al., 2005). Other evidence for a role of Cdk 5 in memory formation is the finding that global p 35 knock-out mice (which leads to reduced brain Cdk5 activity) demonstrated impaired spatial memory formation (Ohshima et al., 2005). These data, however, are difficult to interpret, because they may be attributable to compensatory developmental changes in the mutant mice that led to the spatial memory deficits. Sherry and Crowe (2008) also reported that in chicks, injections of the Cdk5 inhibitor roscovitine impair the consolidation and reconsolidation of passive avoidance memories, but the brain site(s) involved in these effects are unknown.

The mechanisms underlying the effects of inhibition of Cdk5 on consolidation and reconsolidation of cocaine cue memories in our study are unknown. Two potential mediators of these effects are PAK-1, a Cdk5 substrate that regulates actin dynamics (Bokoch, 2003), and the NMDA receptor complex. Thus, transient overexpression of hippocampal Cdk5 activity also causes increased expression of PAK-1 and the NR2A NMDA subunit (Fischer et al., 2005). PAK-1 plays a role in septo-hippocampal Cdk5 mediation of the acquisition and extinction of fear memories (Sananbenesi et al., 2007). Regarding the NMDA receptor, Cdk5 regulates the NR2B NMDA receptor subunit, which modulates synaptic plasticity (Zhang et al., 2008). Additionally, Cdk5 phosphorylates the NR2A NMDA receptor subunit at Ser-1232, and NMDA-evoked current in hippocampal neurons is reduced by the Cdk5 inhibitor roscovitine (Li et al., 2001). Thus, we propose that Cdk5 activity in the BLA controls the consolidation and reconsolidation of cocaine cue memories by regulating the phosphorylation of specific NMDA receptor subunits and NMDAmediated electrical current of local glutamatergic cells.

\section{Role of Cdk5 in cocaine behavioral effects}

Our studies on the role of Cdk5 in the behavioral effects of cocaine in the CPP procedure were inspired in part by work of Bibb, Taylor, and colleagues on the role of Cdk5 in the striatum in cocaine-induced neuroadaptations and the effect of inhibition of Cdk5 activity in the nucleus accumbens on cocaine behavioral effects (Bibb et al., 1999; Benavides and Bibb, 2004; Taylor et al., 2007). However, although we found that inhibition of Cdk5 activity in the BLA inhibits cocaine effects in the CPP procedure, these investigators found that inhibition of C $\mathrm{dk} 5$ in the accumbens reverses cocaine-induced neuroadaptations [proliferation of dendritic spines in the nucleus accumbens (Norrholm et al., 2003)] and potentiates cocaine behavioral effects in several tasks (Benavides et al., 2007; Taylor et al., 2007). Thus, Benavides et al. (2007) reported that viral-mediated knockdown of Cdk5 in the nucleus accumbens enhanced cocaine locomotor sensitization and cocaine CPP. Additionally, Taylor et al. (2007) reported that inhibition of Cdk 5 activity in the nucleus accumbens by the Cdk 5 inhibitor roscovitine causes long-lasting enhanced (1) cocaine psychomotor sensitization, (2) cocaine-induced potentiation of responding for a cue previously paired with a nondrug reward in the conditioned reinforcement procedure (Robbins, 1975; Taylor and Robbins, 1984), and (3) cocaine rewarding effects, as assessed in the progressive ratio reinforcement procedure (Hodos, 1961; Richardson and Roberts, 1996). Bibb, Taylor, and colleagues proposed that the inhibitory effect of striatal Cdk 5 on cocaine behavioral effects is attributable to Cdk5 inhibition of DARPP-32-PKA (protein kinase A)-mediated dopamine signaling and striatal neuronal excitability (Bibb et al., 1999; Benavides and Bibb, 2004; Takahashi et al., 2005; Benavides et al., 2007).

The reasons for putative opposite effects of Cdk5 activity in the BLA and nucleus accumbens on cocaine behavioral effects are unknown. In this regard, it is particularly puzzling that Cdk5 activity in the BLA (current study) and nucleus accumbens (Benavides et al., 2007) had opposite effects in the same behavioral procedure: cocaine CPP. However, in reconciling these differences, it should be noted that, in addition to the different brain sites, our study and the study of Benavides et al. (2007) differed in other aspects. These include the use of different species (rats vs mice), different manipulations for inhibiting Cdk5 activity [a pharmacological agent vs an AAV (adenoassociated virus) vector], and the timing of inhibition of Cdk5 activity (after cocaine exposure vs before cocaine exposure).

\section{Concluding remarks}

In summary, we first demonstrated that cocaine $\mathrm{CPP}$ is associated with increased Cdk5 activity in the BLA. We then performed additional experiments using the Cdk5 inhibitor $\beta$-butyrolaxtone to demonstrate a functional role of amygdala Cdk5 activity in consolidation and reconsolidation of cocaine cue memories, as assessed in the CPP procedure.

\section{References}

Bardo MT, Bevins RA (2000) Conditioned place preference: what does it add to our preclinical understanding of drug reward? Psychopharmacology (Berl) 153:31-43.

Benavides DR, Bibb JA (2004) Role of Cdk5 in drug abuse and plasticity. Ann N Y Acad Sci 1025:335-344.

Benavides DR, Quinn JJ, Zhong P, Hawasli AH, DiLeone RJ, Kansy JW, Olausson P, Yan Z, Taylor JR, Bibb JA (2007) Cdk5 modulates cocaine reward, motivation, and striatal neuron excitability. J Neurosci 27:12967-12976.

Beninger RJ, Gerdjikov T (2004) The role of signaling molecules in rewardrelated incentive learning. Neurotox Res 6:91-104.

Bernardi RE, Ryabinin AE, Berger SP, Lattal KM (2009) Post-retrieval disruption of a cocaine conditioned place preference by systemic and intrabasolateral amygdala beta2- and alpha1-adrenergic antagonists. Learn Mem 16:777-789.

Bibb JA, Snyder GL, Nishi A, Yan Z, Meijer L, Fienberg AA, Tsai LH, Kwon YT, Girault JA, Czernik AJ, Huganir RL, Hemmings HC Jr, Nairn AC, Greengard P (1999) Phosphorylation of DARPP-32 by Cdk5 modulates dopamine signalling in neurons. Nature 402:669-671.

Bibb JA, Chen J, Taylor JR, Svenningsson P, Nishi A, Snyder GL, Yan Z, Sagawa ZK, Ouimet CC, Nairn AC, Nestler EJ, Greengard P (2001) Effects of chronic exposure to cocaine are regulated by the neuronal protein Cdk5. Nature 410:376-380.

Bokoch GM (2003) Biology of the p21-activated kinases. Annu Rev Biochem 72:743-781.

Cervo L, Mukherjee S, Bertaglia A, Samanin R (1997) Protein kinases A and $\mathrm{C}$ are involved in the mechanisms underlying consolidation of cocaine place conditioning. Brain Res 775:30-36.

Chae T, Kwon YT, Bronson R, Dikkes P, Li E, Tsai LH (1997) Mice lacking p35, a neuronal specific activator of Cdk5, display cortical lamination defects, seizures, and adult lethality. Neuron 18:29-42.

Chen PC, Chen JC (2005) Enhanced Cdk5 activity and p35 translocation in the ventral striatum of acute and chronic methamphetamine-treated rats. Neuropsychopharmacology 30:538-549.

Cheung ZH, Fu AK, Ip NY (2006) Synaptic roles of Cdk5: implications in higher cognitive functions and neurodegenerative diseases. Neuron 50:13-18.

Ciccocioppo R, Martin-Fardon R, Weiss F (2004) Stimuli associated with a 
single cocaine experience elicit long-lasting cocaine-seeking. Nat Neurosci 7:495-496.

Dhavan R, Tsai LH (2001) A decade of CDK5. Nat Rev Mol Cell Biol 2:749-759.

Dudai Y (2006) Reconsolidation: the advantage of being refocused. Curr Opin Neurobiol 16:174-178.

Everitt BJ, Robbins TW (2000) Second-order schedules of drug reinforcement in rats and monkeys: measurement of reinforcing efficacy and drugseeking behaviour. Psychopharmacology 153:17-30.

Everitt BJ, Belin D, Economidou D, Pelloux Y, Dalley JW, Robbins TW (2008) Review. Neural mechanisms underlying the vulnerability to develop compulsive drug-seeking habits and addiction. Philos Trans R Soc Lond B Biol Sci 363:3125-3135.

Fischer A, Sananbenesi F, Schrick C, Spiess J, Radulovic J (2002) Cyclindependent kinase 5 is required for associative learning. J Neurosci 22:3700-3707.

Fischer A, Sananbenesi F, Schrick C, Spiess J, Radulovic J (2003a) Regulation of contextual fear conditioning by baseline and inducible septo-hippocampal cyclin-dependent kinase 5. Neuropharmacology 44:1089-1099.

Fischer A, Sananbenesi F, Spiess J, Radulovic J (2003b) Cdk5: a novel role in learning and memory. Neurosignals 12:200-208.

Fischer A, Sananbenesi F, Pang PT, Lu B, Tsai LH (2005) Opposing roles of transient and prolonged expression of p25 in synaptic plasticity and hippocampus-dependent memory. Neuron 48:825-838.

Fuchs RA, Feltenstein MW, See RE (2006) The role of the basolateral amygdala in stimulus-reward memory and extinction memory consolidation and in subsequent conditioned cued reinstatement of cocaine seeking. Eur J Neurosci 23:2809-2813.

Goldberg SR (1975) Stimuli associated with drug injections as events that control behavior. Pharmacol Rev 27:325-340.

Hodos W (1961) Progressive ratio as a measure of reward strength. Science 134:943-944.

Kansy JW, Daubner SC, Nishi A, Sotogaku N, Lloyd MD, Nguyen C, Lu L, Haycock JW, Hope BT, Fitzpatrick PF, Bibb JA (2004) Identification of tyrosine hydroxylase as a physiological substrate for Cdk5. J Neurochem 91:374-384.

Kruzich PJ, See RE (2001) Differential contributions of the basolateral and central amygdala in the acquisition and expression of conditioned relapse to cocaine-seeking behavior. J Neurosci 21:RC155(1-5).

Lee JL, Di Ciano P, Thomas KL, Everitt BJ (2005) Disrupting reconsolidation of drug memories reduces cocaine-seeking behavior. Neuron 47:795-801.

Lee JL, Milton AL, Everitt BJ (2006) Cue-induced cocaine seeking and relapse are reduced by disruption of drug memory reconsolidation. J Neurosci 26:5881-5887.

Li BS, Sun MK, Zhang L, Takahashi S, Ma W, Vinade L, Kulkarni AB, Brady RO, Pant HC (2001) Regulation of NMDA receptors by cyclindependent kinase-5. Proc Natl Acad Sci U S A 98:12742-12747.

Li YQ, Li FQ, Wang XY, Wu P, Zhao M, Xu CM, Shaham Y, Lu L (2008) Central amygdala extracellular signal-regulated kinase signaling pathway is critical to incubation of opiate craving. J Neurosci 28:13248-13257.

Lu L, Grimm JW, Hope BT, Shaham Y (2004) Incubation of cocaine craving after withdrawal: a review of preclinical data. Neuropharmacology 47 [Suppl 1]:214-226.

Lu L, Hope BT, Dempsey J, Liu SY, Bossert JM, Shaham Y (2005) Central amygdala ERK signaling pathway is critical to incubation of cocaine craving. Nat Neurosci 8:212-219.

Lu L, Uejima JL, Gray SM, Bossert JM, Shaham Y (2007) Systemic and central amygdala injections of the mGluR(2/3) agonist LY379268 attenuate the expression of incubation of cocaine craving. Biol Psychiatry 61:591-598.

McGaugh JL (1966) Time-dependent processes in memory storage. Science 153:1351-1358.

McGaugh JL (2000) Memory-a century of consolidation. Science 287: $248-251$.

McGaugh JL (2004) The amygdala modulates the consolidation of memories of emotionally arousing experiences. Annu Rev Neurosci 27:1-28.

Miller CA, Marshall JF (2005) Molecular substrates for retrieval and reconsolidation of cocaine-associated contextual memory. Neuron 47:873-884.

Misanin JR, Miller RR, Lewis DJ (1968) Retrograde amnesia produced by electroconvulsive shock after reactivation of a consolidated memory trace. Science 160:554-555.
Mucha RF, van der Kooy D, O'Shaughnessy M, Bucenieks P (1982) Drug reinforcement studied by the use of place conditioning in rat. Brain Res 243:91-105.

Mueller D, Stewart J (2000) Cocaine-induced conditioned place preference: reinstatement by priming injections of cocaine after extinction. Behav Brain Res 115:39-47.

Nader K, Schafe GE, Le Doux JE (2000) Fear memories require protein synthesis in the amygdala for reconsolidation after retrieval. Nature 406:722-726.

Nikolic M, Chou MM, Lu W, Mayer BJ, Tsai LH (1998) The p35/Cdk5 kinase is a neuron-specific Rac effector that inhibits Pak1 activity. Nature 395:194-198.

Norrholm SD, Bibb JA, Nestler EJ, Ouimet CC, Taylor JR, Greengard P (2003) Cocaine-induced proliferation of dendritic spines in nucleus accumbens is dependent on the activity of cyclin-dependent kinase-5. Neuroscience 116:19-22.

O'Brien CP, Childress AR, McLellan AT, Ehrman R (1992) Classical conditioning in drug-dependent humans. Ann N Y Acad Sci 654:400-415.

Ohshima T, Ward JM, Huh CG, Longenecker G, Veeranna, Pant HC, Brady RO, Martin LJ, Kulkarni AB (1996) Targeted disruption of the cyclindependent kinase 5 gene results in abnormal corticogenesis, neuronal pathology and perinatal death. Proc Natl Acad Sci U S A 93:11173-11178.

Ohshima T, Ogura H, Tomizawa K, Hayashi K, Suzuki H, Saito T, Kamei H, Nishi A, Bibb JA, Hisanaga S, Matsui H, Mikoshiba K (2005) Impairment of hippocampal long-term depression and defective spatial learning and memory in p35 mice. J Neurochem 94:917-925.

Paglini G, Cáceres A (2001) The role of the Cdk5-p35 kinase in neuronal development. Eur J Biochem 268:1528-1533.

Paxinos G, Watson C (2005) The rat brain in stereotaxic coordinates, Ed 5. Amsterdam: Elsevier Academic.

Richardson NR, Roberts DC (1996) Progressive ratio schedules in drug selfadministration studies in rats: a method to evaluate reinforcing efficacy. J Neurosci Methods 66:1-11.

Robbins TW (1975) The potentiation of conditioned reinforcement by psychomotor stimulant drugs: a test of Hill's hypothesis. Psychopharmacologia 45:103-114.

Sananbenesi F, Fischer A, Wang X, Schrick C, Neve R, Radulovic J, Tsai LH (2007) A hippocampal Cdk5 pathway regulates extinction of contextual fear. Nat Neurosci 10:1012-1019.

See RE (2002) Neural substrates of conditioned-cued relapse to drugseeking behavior. Pharmacol Biochem Behav 71:517-529.

Sherry JM, Crowe SF (2008) Inhibition of cyclin-dependent kinase 5 by roscovitine impairs memory consolidation and reconsolidation in the day-old chick. Pharmacol Biochem Behav 91:59-66.

Stewart J, de Wit H, Eikelboom R (1984) Role of unconditioned and conditioned drug effects in the self-administration of opiates and stimulants. Psychol Rev 91:251-268.

Takahashi S, Ohshima T, Cho A, Sreenath T, Iadarola MJ, Pant HC, Kim Y, Nairn AC, Brady RO, Greengard P, Kulkarni AB (2005) Increased activity of cyclin-dependent kinase 5 leads to attenuation of cocaine-mediated dopamine signaling. Proc Natl Acad Sci U S A 102:1737-1742.

Taylor JR, Robbins TW (1984) Enhanced behavioural control by conditioned reinforcers following microinjections of D-amphetamine into the nucleus accumbens. Psychopharmacology 84:405-412.

Taylor JR, Lynch WJ, Sanchez H, Olausson P, Nestler EJ, Bibb JA (2007) Inhibition of Cdk5 in the nucleus accumbens enhances the locomotoractivating and incentive-motivational effects of cocaine. Proc Natl Acad Sci U S A 104:4147-4152.

Tronson NC, Taylor JR (2007) Molecular mechanisms of memory reconsolidation. Nat Rev Neurosci 8:262-275.

Tzschentke TM (1998) Measuring reward with the conditioned place preference paradigm: a comprehensive review of drug effects, recent progress and new issues. Prog Neurobiol 56:613-672.

Wang XY, Zhao M, Ghitza UE, Li YQ, Lu L (2008) Stress impairs reconsolidation of drug memory via glucocorticoid receptors in the basolateral amygdala. J Neurosci 28:5602-5610.

Wikler A (1973) Dynamics of drug dependence, implication of a conditioning theory for research and treatment. Arch Gen Psychiatry 28:611-616.

Zhang S, Edelmann L, Liu J, Crandall JE, Morabito MA (2008) Cdk5 regulates the phosphorylation of tyrosine $1472 \mathrm{NR} 2 \mathrm{~B}$ and the surface expression of NMDA receptors. J Neurosci 28:415-424. 